\title{
The Application of Asphalt Cold Recycling Technology in Lower Yellow River Flood Control Project
}

\author{
Yu Kun ZHAO ${ }^{1}$, Qing An LI \\ ${ }^{1}$ Engineering Construction Center, Yellow River Shandong Bureau, Jinan, 250011, China \\ ${ }^{2}$ Reconnaissance, Design and Research Institute of Yellow River Shandong, Jinan, 250013, China
}

\begin{abstract}
Asphalt cold recycling technology has many advantages, such as rapid construction, energy saving, and environmental protection. In this article, the works based on the flood control dike road repair of lower Yellow River flood control project and cold asphalt recycling technology. Combined with the current flood control dike road in Liaocheng, the old pavement rehabilitation program was designed and the program was successfully implemented. It provided a successful reference cases for application of asphalt cold recycling technology for flood control dike road repair in the lower Yellow River flood control project.
\end{abstract}

\section{THE PURPOSE AND SIGNIFICANCE OF ASPHALT RECYCLING TECHNOLOGY}

Asphalt recycling technology was asphalt pavement material recycling technology, it was the entire process technology that the old asphalt pavement needed to overhaul or abandoned was added in the right amount of new aggregate, new asphalt after scarifying, recycling, crushing, screening, and then re-mixed into a good road performance of recycled asphalt mix, for pavement surface or substrate.

Recycled asphalt pavement materials, could save a lot of asphalt and gravel material, thus saving engineering investment. At the same time, it was beneficial to handling of waste, energy conservation, environmental protection, which had a significant economic and social benefits.

\section{THE MECHANISM AND TECHNICAL REQUIREMENTS OF ASPHALT RECYCLING TECHNOLOGY}

The key of recycled asphalt pavement materials was regenerated asphalt. Recycled asphalt was the reverse process of asphalt aging. In the aging old asphalt, adding a certain component of low viscosity oil (regeneration agent), or adding an appropriate consistency of bituminous materials, with scientific and rational process, recycled asphalt having a suitable viscosity and meeting the performance requirements of pavement was deployed out. Contrasting old asphalt, the composite fluidity of recycled asphalt had improved greatly, and the rheological properties was greatly improved.

The technical requirements for regenerated catalyst were I a softening penetration, that had the appropriate viscosity, II good rheological properties, that showed Newtonian liquid nature, III the ability to disperse and dissolve asphaltenes, which had rich aromatic phenol, IV a high surface tension, $V$ good heat resistance and weather resistance.

According reproduction mode, regeneration sites, the use of mechanical devices, the asphalt recycling technology could be divided into hot or cold mix 
recycling technology, artificial or mechanical mixing technology, mixed in factory or field.

\section{PROJECT OVERVIEW}

Landforms of lower Yellow River were plains, hills and mountains, the main topography was plain. The implementation of the project object was the road on certain flood control dike of Liaocheng left bank facing Lower Yellow River. Earth's surface of project area was consistent with the loose deposits composition of Quaternary, geotechnical properties was mainly decided by light loam, silt, clay and other components. The thickness was uniformity, and the layer was stable. Engineering regional was belongs to the warm temperate monsoon climate zone, it was a semi-humid continental climate.

The damaged road flood control dike located between embankment Stake $9+800$ to $59+200$, the total length was $6.24 \mathrm{~km}$. Road situation was showed in Figure 1. In this project, the flood control dike road damaged by construction was to be repaired.

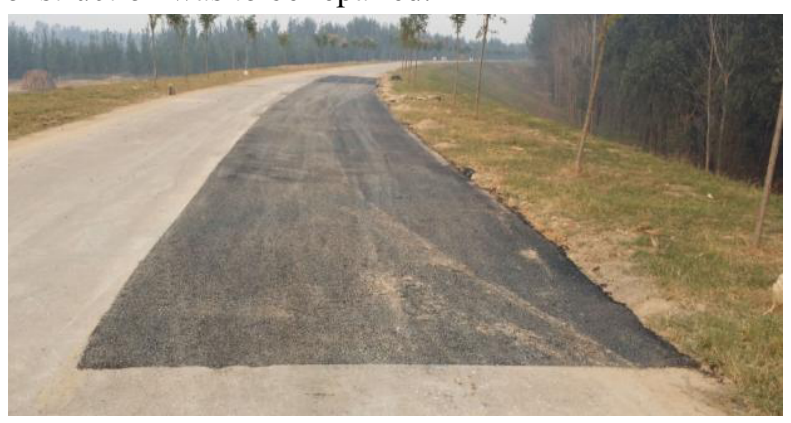

Figure 1. Road situation

\section{ASPHALT RECYCLING TECHNOLOGY DESIGN IN ENGINEERING PROJECTS}

\subsection{Survey for old Road ${ }^{[1-2]}$}

After site survey, asphalt pavement diseases of flood control dike road was mainly longitudinal cracks, transverse cracks, network cracks and other diseases. Pavement condition detection for flood control dike road applied pavement deflection tests, coring test, flatness and breakage detection. The detection was sampling test. The total detection length was $5.2 \mathrm{~km}$.

After testing, the damage extent of pavement had been assessed as poor, the road flatness was evaluated as a secondary, the structural strength of pavement was evaluated as poor, surface layer thickness was in the range
$4.0-5.0 \mathrm{~cm}$. The base material was lime stable detritus soil, the gravel particle size was larger. The conjugates of lime, soil and gravel failed to form a base layer with a certain intensity, most of the core sample was fragmented.

\subsection{Pavement repair design}

Because of the original dike road renovations, the dike road grade was surveyed and designed according to original flood control dike standards. Consider the characteristics such as less daily traffic on flood control dike road, a sudden increase traffic in flood season, alarge tonnage of emergency vehicles, and relatively slow speed of traffic, the road design referenced in plain three road standards. However, due to the irregularity of dike line layout, flat route could not meet the requirements of tertiary roads, the graphic design made appropriate adjustments by lower standards combined with the specific circumstances. The design of pavement structure type was refered to builted highway in the project area, and accorded with the principles of local conditions, a reasonable selection, convenient construction and convenient conservation.

For the renovation of the road surface, first poured process for the cracks in the original pavement structure, then cleared road surface dust, debris and brushing sticky asphalt, hot mix asphalt concrete was paved $5 \mathrm{~cm}$ finally.

For general grassroots renovated sections(old asphalt surface was $5 \mathrm{~cm}$ thickness, lime stable detritus soil was 8 $\sim 10 \mathrm{~cm}$ thickness, gravel aggregate increase was $6 \sim 8 \mathrm{~cm}$ thickness), the $20 \mathrm{~cm}$-cement cold recycling was constructed and then $5 \mathrm{~cm}$-hot mix asphalt concrete was paved.

Considering project cost, construction technology, construction period, energy saving, construction equipment, etc. the program was that the project cost was lower, the construction technology is mature, the construction period was moderate, the pavement strength was better. Those were well done, waste treatment, energy conservation and environmental protection. There was no the problem of random release of old asphalt and waste arbitrary.

The used equipments were WR2500S type Wirtgen cold recycling machine, motor graders, rollers, water tankers, hot asphalt mixing station and hot asphalt paver. 


\section{THE IMPLEMENTATION OF ASPHALT RECYCLING TECHNOLOGY IN THE PROJECT ${ }^{[3-5]}$}

\subsection{Construction preparation}

\subsubsection{Traffic}

Since the road along the flood control dike crossed numerous local roads, the outbound traffic was in good condition. Stone, oilseeds, living materials and others directly accessed to the construction area. Use of existing flood control dike road, construction and traffic road in construction zone could be built temporary roads as needed. During construction, the construction section was closed to traffic. Construction plan should be reasonable organization by segmented construction approach. Vehicles can bypass the construction area by the upstream or downstream Voeux Road of the construction segment and construction detour.

\subsubsection{Material}

The cement applied in regeneration mix is used ordinary portland cement. The initial setting time of the cement was required more than $3 \mathrm{~h}$, and the final setting time $6 \mathrm{~h}$ above. The rapid hardening cement, early strength cement and damp cement should not be used. The cement should be loose and dried, no lumps and damp cement. The cement strength class of 32.5 or 42.5 can be chose. The aggregates and water should meet the specifications. When the cement stabilized CIR layer used as a base layer, the maximum diameter of the individual particles should not exceed $37.5 \mathrm{~mm}$.

When the cement stabilized CIR layer used as a base layer, the minimum dose of cement should not be less than $4 \%$. But the strength of the cement regenerated mixture can not be got by increasing the cement content, cement doses should not exceed 5.5\%.

\subsubsection{Equipment}

The used equipments were one dedicated in-situ cold recycling equipment for Wirtgen WR2000 / WR2500S Cold Recycling Machine, two water tankers, two single drum compactor, one motor grader, one sprinkler, one rubber tire roller above $20 \mathrm{t}$ with spray function intact.

\subsection{Construction technology}

After the preparatory work, the formal construction was officially started. The cement stabilized in situ cold recycling process should be carried out in the order of FIG. 2.

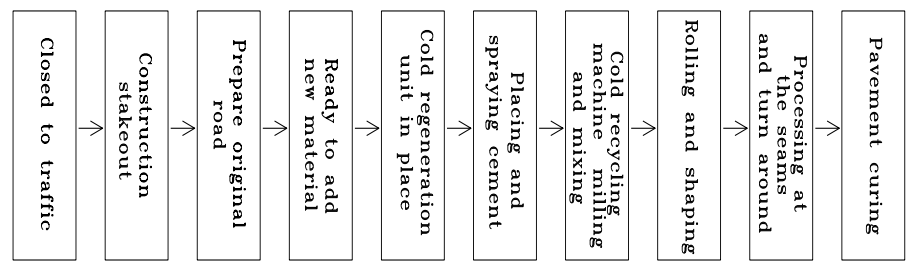

Figure 2. Cement stabilized cold recycling process

\subsubsection{Cold recycling machine milling and mixing}

The water content of regeneration mixture should be controlled in range $0.5 \%$ to $1.0 \%$ of optimum moisture content. The cold recycling machine pushed slurry or tankers traveling on the old pavement. The travel speed of the cold recycling machine is controlled within the $6 \mathrm{~m} /$ $\min \sim 12 \mathrm{~m} /$ min range.

After the recycling machine, professionals control the construction quality. The professionals always checked the regeneration depth, cement content and water content, and recycling machine operator adjusted operating the machine with the inspection results. In order to prevent the influence of vertical joints, horizontal joints, flatness and compactness of recycled materials, it was better that 4-5 people should be arranged to handle edges, clean-up the impurities of mixture and the excess material of the first cut after the recycling machine.

The best length of each regeneration was that the follow-up operations can be definitely and normally performed. Construction should be carefully organized so that the length of regeneration was implemented as long as possible, in order to reduce lateral seams. A (non-stop) regeneration length is generally $150 \mathrm{~m} \sim 250 \mathrm{~m}$.

\subsubsection{Rolling and forming}

Drum vibratory rollers should immediately follow the regeneration machine to initially roll. Roller used the high amplitude-low frequency manner to roll, and the compaction passes should be sufficient to ensure that the degree of compaction within the bottom two-thirds thickness range of the reproduction layer meet the requirements. The working speed of the drum compactor could not exceed $3 \mathrm{~km} / \mathrm{h}$ 
After completion of the initial roll, motor grader should be immediately applied shaping. In line segment, motor graders calibrated from both sides of the road to center. In the flat curve segment, motor graders performed calibrating from the inside to the outside. For topical low-lying areas, the surface was harrowed by tooth harrow more than $5 \mathrm{~cm}$, and with a fresh mix for leveling.

When shaping, high material should be directly blew way out, the phenomenon of a thin layer subsidies should not be formed. In the shaping process, vehicular traffic was prohibited, and no significant segregation of thick or thin aggregate was hold.

After shaping, when the water content of the mixture was at optimum moisture content, light wheel roller compacted immediately with the mode of high amplitude low frequency vibration mode firstly and then a low amplitude high frequency mode. In the straight line and no ultra flat curve segment, roller should overlap $1 / 2$ wheel width from the shoulder to the center of rolling Road, and rear wheels must cover two sections seams. When the rear wheels rolled full width of the surface, one rolling was completed. It generally took six to eight times rolling. Roller's rolling speed, was appropriate with the speed of $1.5 \sim 1.7 \mathrm{~km} / \mathrm{h}$ at first and second times, and then $2.0 \sim 2.5 \mathrm{~km} / \mathrm{h}$.

\subsubsection{Pavement curing and traffic control}

Each section of the road was completed rolling and the compaction degree was inspection and approval, it should immediately begin to cut off traffic and curing. When using mulch curing method, the cover must be cleaned after the curing. The curing period of grassroots should not be less than $7 \mathrm{~d}$.

After the curing period, the grass roots should be cleaned, and asphalt penetration oil layer and asphalt adhesive oil layer were immediately sprayed. After spraying penetration oil layer or adhesive oil layer of asphalt, small pieces or gravel with diameter of $5-10 \mathrm{~mm}$ should be evenly spread, and the amount of the stone was about the $60 \%-70 \%$ of the amount of whole layer of stone. After the curing of the regeneration layer, surface construction was completed before open traffic.

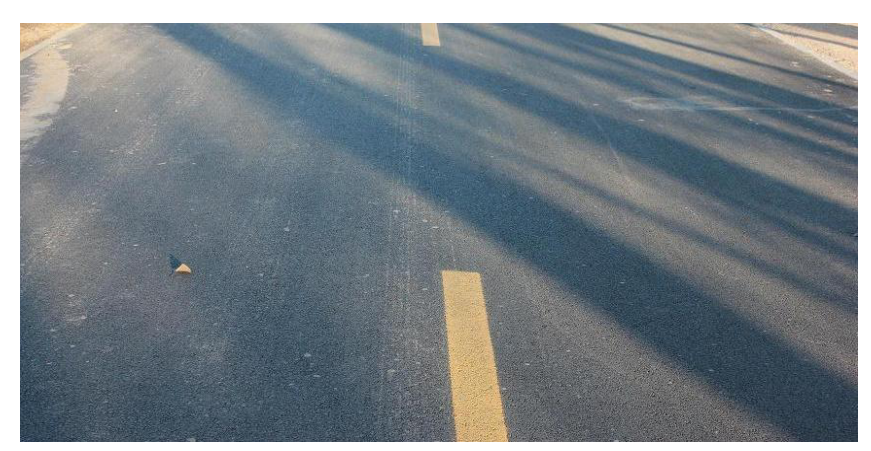

Figure 3. Flood control road situation after the restoration

\section{CONCLUSION}

I This project of the asphalt pavement cold recycling technology was first applied for road repairing in Shandong Yellow River flood control dike. Compared with traditional methods of renovation, cold recycling technology has obvious advantages. The application was successful, it can provided a reference for dike road repair construction in lower Yellow River flood control dike.

II Asphalt cold recycling technology was constructed on base or sub base. Through the old asphalt pavement crushing, mixing, shaping, and rolling, asphalt cold recycling technology accelerated the construction schedule and reduced environmental pollution. In today's emphasis on sustainable development, asphalt recycling technology has particular significance for the development of highway construction.

\section{REFERENCES}

1. JTG F41-2008, Technical Specifications for Highway Asphalt Pavement Recycling [S].

2. JTJ 034-2000, Technical Specifications for Construction of Highway Roadbases [S].

3. YI Qigui. Application of Cement Stabilized Macadam Base Cold in-palce Recycling Technology and Its Economical Efficiency[J]. Highway Construction \& Maintenance, 2011 (3/4) : 91-95.

4. FENF Yinfu, ZHU Haizhe. The Research on Cement Full Deep Cold in-place Recycling Base Application[J]. Shanxi Science \& Technology of Communications, 2013(3):3-5.

5. JIN Fang, LIU Yue, XUE Liang. The Application of Cold Recycling Technology in-Place to Municipal Road Reconstruction [J]. Shanxi Science \& Technology of Communications , 2013(1):20-21,24. 